\title{
Elective and emergency selective renal artery angio- graphy and embolization of angiomyolipoma: a report of two cases and review of the literature
}

\author{
Anthony Kodzo-Grey Venyo, Emad Bakir \\ Departments of Urology and Radiology, North Manchester General Hospital, Manchester, United Kingdom
}

Correspondence: Anthony Kodzo-Grey Venyo. Address: Department of Urology, North Manchester General Hospital, Manchester, United Kingdom. Email: akodzogrey@yahoo.co.uk

Received: April 8, 2012

DOI : $10.5430 /$ jbgc.v2n1p101

\author{
Accepted: April 22, $2012 \quad$ Published: June 1, 2012 \\ URL: http://dx.doi.org/10.5430/jbgc.v2n1p101
}

\begin{abstract}
Objectives: With developments in interventional radiology, selective renal artery angiography and super-selective embolization is gradually being used as an alternative treatment modality for angiomyolipoma of the kidney instead of nephrectomy or partial nephrectomy. It has been suggested that the use of steroids around the time of embolization may reduce or avoid post-embolization syndrome. Our aim is to report two cases of angiomyolipoma of kidney that were treated electively and as an emergency procedure with a review of the literature.

Methods: Detailed clinical records of the two patients were obtained from their case notes, ALS records of clinic letters and discharge summaries, PACS system for records of all radiological procedures, computerized results of all laboratory tests in order to document the presentation, investigation, management and outcome of management of the patients. Literature was reviewed on embolization of angiomyolipoma of the kidney.

Results: Two patients with angiomyolipoma of the kidney, (the first patient a lady with an enlarging angiomyolipoma of the right kidney and the second patient a lady who had spontaneous haemorrhage into a large angiomyolipoma of her right kidney), underwent selective right renal artery angiography and supers-selective embolization of the feeding vessels of their angiomyolipomas. The first patient was given steroid cover (Hydrocortisone and prednisolone) for two weeks in order to reduce or minimise the development of post-embolization syndrome. The second patient was not given any steroid cover. The first patient was discharged home on the first day after her embolization procedure and she did not develop any complications. The second patient who was not given any steroid cover developed post-embolization syndrome which eventually resolved after about six weeks. Literature review indicates that post-embolization syndrome is common after embolization. There is some evidence in the literature to suggest that the use of a short course of steroids around the time of embolization procedure reduces or prevents the development of post-embolization syndrome.
\end{abstract}

Conclusions: Selective renal artery angiography can be used to diagnose a non-bleeding-angiomyolipoma, as well as bleeding enlarged angiomyolipoma of kidney. Super-selective renal artery embolization of a large angiomyolipoma of the kidney is a useful alternative to partial nephrectomy or full nephrectomy; it has the advantage of not requiring general anaesthesia and it is associated with less morbidity than nephrectomy or partial nephrectomy. Our limited experience and 
literature review would suggest that perhaps the use of steroids around the time of embolization may reduce the incidence of post-embolization syndrome.

\section{Key words}

Angiomyolipoma, Bleeding, Pain, Angiography, Embolization, Post-Embolization Syndrome, Prednisolone, Hydrocortisone, CT-scan

\section{I ntroduction}

Renal Angiomyolipoma (AML) is a benign hamartomatous tumour which contains smooth muscle, fat, and abnormal vessels in varying proportions. There are two recognised types of angiomyolipoma which include:

- The sporadic type of angiomyolipoma, which is a single tumour that occurs mainly in the older age group (50-80 years); it is predominant among women; it constitutes $80 \%$ of all cases of angiomyolipoma.

- The second type of angiomyolipoma is associated with tuberous sclerosis (TS), also called epiloia and other types of phakomatosis; it is also predominant among women. This type of angiomyolipoma is symptomatic with multiple bilateral lesions and these constitute $20 \%$ of all renal angiomyolipomas ${ }^{[1-3]}$.

The term angiomyolipoma (AML) has been attributed to Morgan and associates in $1951^{[4]}$. The renal lesion which histologically corresponds to renal angiomyolipoma, was first described by Grawitz in $1900^{[5]}$.

Renal angiomyolipoma (AML) was previously considered a rare tumour with the diagnosis established by histology after removal of the renal lesion. Angiomyolipoma of the kidney is now recognised as a fairly common lesion with a broad range of sequelae which can be managed by means of different management options.

Spontaneous renal haemorrhage secondary to renal angiomyolipoma or Wunderlich syndrome is rare.

Spontaneous non-traumatic bleeding confined to the sub-capsular or perinephric space in patients with no known underlying cause was first described as "Spontaneous renal capsular apoplexy" by Carl Reinhold August Wunderlich in 1856. The presentation of this clinical picture varies greatly depending upon the duration and degree of the haemorrhage. Most commonly, acute lumbo-abdominal pain, nausea, vomiting haematuria, hemodynamic instability, hypovolemic shock and anaemia are the observed features. A variety of causes are involved including:

- Benign and malignant neoplasms

- Vascular disease - vasculitis; renal arteriosclerosis; renal artery aneurysm rupture

- Nephritis

- Infections

- Undiagnosed haematological disorders

- Anatomical lesions

Wunderlich's syndrome is one of the most feared complications of renal angiomyolipoma which can be fatal if not treated promptly and aggressively.

Developments in interventional radiology have been helpful with regard to the diagnosis and treatment of angiomyolipoma of the kidney.

Two cases of angiomyolpoma are reported which have been managed by selective renal artery angiography and embolization (one with steroid cover and the second without steroid cover) with a review of the literature. 


\section{Case reports}

\subsection{Case number 1}

An 81-year-old lady who had anterior resection for Duke’s stage B adenocarcinoma in 2001 had surveillance CT scan in 2010 which revealed angiomyolipoma in the lower pole of her right kidney. The radiologist reported that there was a large exophytic fat density mass measuring $6 \mathrm{~cm} \times 4.4 \mathrm{~cm} \times 6.1 \mathrm{~cm}$ in the interpolar region of the right kidney which was suggestive of angiomyolipoma. There was also a $10 \mathrm{~mm}$ lesion in the upper pole of the right kidney which was suggestive probably of lobulated renal parenchyma or a high density renal cyst. She was therefore referred to the urology team. Her case was discussed at the Urology multi-disciplinary team (MDT) meeting when her CT scan was reviewed. The MDT recommended that she should be kept under surveillance and she should have repeat CT scans at subsequent intervals. She had a repeat CT scan six months later which did not reveal any change in the appearance of the right renal mass.

It was noted that her haemoglobin level had dropped over the preceding 3 months from $11.0 \mathrm{~g} / \mathrm{dl}$ to $9.5 \mathrm{~g} / \mathrm{dl}$. She had no history of blood loss anywhere in the form of haematuria, bleeding per rectum, haematemesis or haemoptysis. She had colonoscopy and upper gastro-intestinal endoscopy which were normal. She had CT-scan of the thorax and abdomen which revealed no evidence of any lesion in her thorax but it revealed a $6.4 \mathrm{~cm}$ angiomyolipoma in the lower pole of her right kidney (see Figure 1). Her urine examination by flow cytometry as well as culture and cytology were normal. Her other investigations including serum urea and electrolytes, liver function tests, carcinoembryonic antigen levels, B12 and folate levels were normal. Her general and abdominal examinations were unremarkable apart from mild tenderness in both of her flanks. She was therefore put on iron tablets and the urologist was asked to review her.

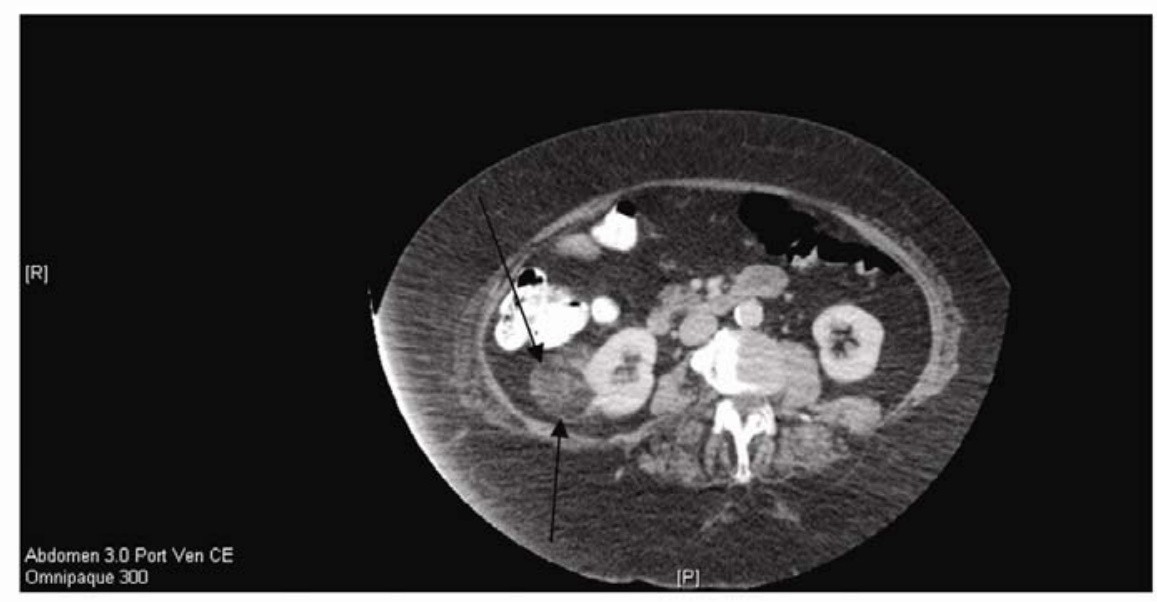

Figure 1. CT-scan of abdomen 6 months after the initial CT-scan showing angiomyolipoma involving right kidney (see arrow)

At her next urology consultation, her most recent CT scan was reviewed and it was explained to her that the angiomyolipoma in her right kidney was large (about $6.4 \mathrm{~cm}$ ). It was also explained to her that in view of the large size of the angiomyolipoma there was a great chance that she would develop spontaneous bleeding into the angiomyolipoma, therefore, it would be advisable for her to under-go selective angiography and embolization of the angiomyolipoma electively. She agreed to undergo the procedure and was listed for the procedure.

During admission for the embolization procedure she had investigations including full blood count, serum urea and electrolytes, liver function tests, bone profile, estimated glomerular filtration rate and a coagulation screen which were essentially normal with the actual results reported as follows: 
- Full blood count - Haemoglobin $12.7 \mathrm{~d} / \mathrm{dl}$ (normal range 11.5 - 16.5); white blood cell count $4.3 \times 10^{9} / \mathrm{L}$ (normal range 4.0 - 11.0); platelets $237 \times 10^{9} / \mathrm{L}$ (normal range 150 - 450)

- $\quad$ INR - 1.0 (normal range 0.9-1.1)

- $\quad$ PT - 11.6 s (normal range $10-16$ )

- Fibrinogen derived $4.7 \mathrm{~g} / \mathrm{l}$ (normal range 1.7 - 4.0) [level high]

- Serum sodium $142 \mathrm{~m}-\mathrm{mol} / \mathrm{L}$ (normal range 136 - 145); serum potassium $4.0 \mathrm{~m}-\mathrm{mol} / \mathrm{L}$ (3.5 - 5.4); serum creatinine $74 \mathrm{u}-\mathrm{mol} / \mathrm{L}$ (normal range 53 - 97); serum urea $6.3 \mathrm{~m}-\mathrm{mol} / \mathrm{L}$ (normal range 2.5 - 6.7)

- Liver and bone profile-Serum bilirubin - $18 \mathrm{umol} / \mathrm{L}$ (normal range 3-21); serum ALT $10 \mathrm{u} / \mathrm{L}$ (normal range 10-35); serum alkaline phosphatase $77 \mathrm{u} / \mathrm{L}$ (normal range 30-150); serum albumin $36 \mathrm{~g} / \mathrm{L}$ (normal range 35-50); serum calcium $2.39 \mathrm{mmol} / \mathrm{L}$ (normal range 2.10-2.60); serum calcium corrected $2.47 \mathrm{mmol} / \mathrm{L}$ (2.10-2.60).

- $\quad$ Estimated GFR - eGFR [MDRD formula) $63 \mathrm{~mL} / \mathrm{min}$ (normal range > 60).

She underwent selective right renal artery angiography which revealed a right renal angiomyolipoma which was supplied by a branch of the renal artery. Selective embolization of the angiomyolipoma was done using coils with good results and with no complications (see Figures 2 to 4 for the angiography and the post embolization images). The procedure was done after she had been given intramuscular injections of pethidine $50 \mathrm{mg}$, maxolon $10 \mathrm{mg}$ and ciprofloxacin $500 \mathrm{mg}$ orally. On the day of the embolization she had $100 \mathrm{mg}$ of intramuscular hydrocortisone injection intramuscularly post procedure and she had another $100 \mathrm{mg}$ of hydrocortisone injection on the first post embolization day. She was also started on $10 \mathrm{mg}$ of prednisolone orally daily on the first day post embolization.

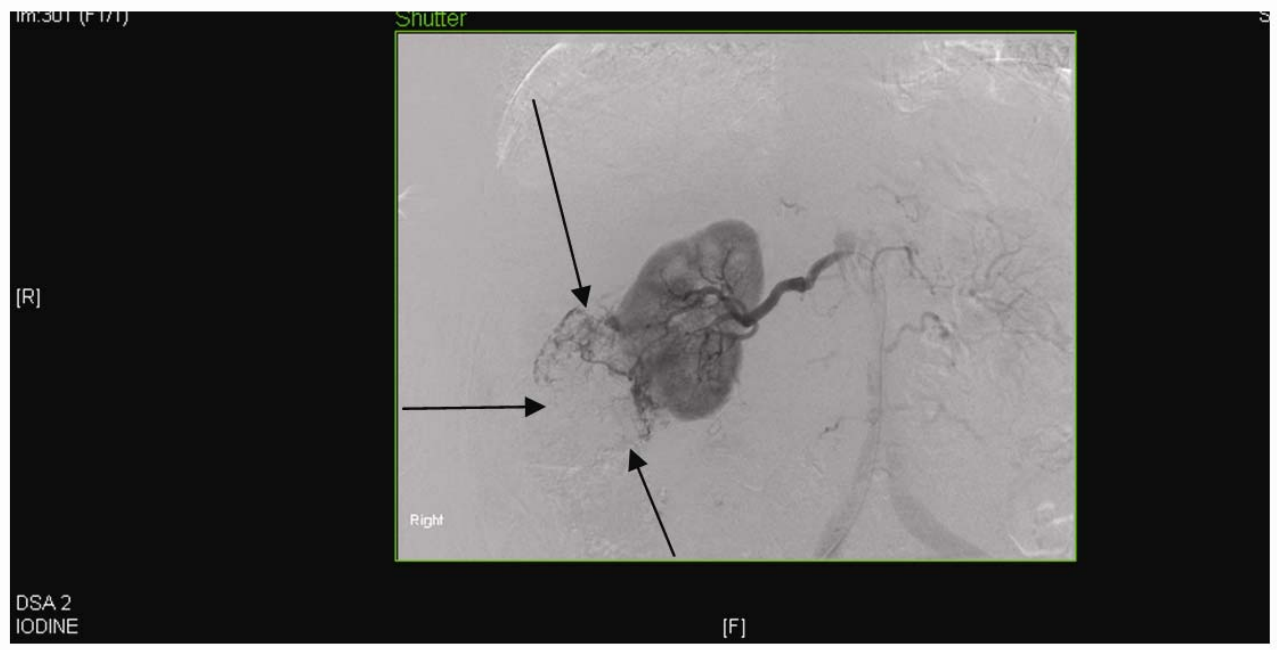

Figure 2. Angiography at beginning of embolization showing angiomyolipoma involving the mid-pole of right kidney (outer aspect) with feeding vessels (see arrows)

She was remarkably well post embolization of her angiomyolipoma without any fever, vomiting/nausea or pain. On the first day following her embolization procedure she had blood tests including full blood count, serum urea and electrolytes, liver function tests, bone profile, serum C Reactive Protein (serum CRP) which were all essentially normal. The results were reported as follows:

- Full blood count: haemoglobin 13.6 g/dl; white blood cell count $7.6 \times 10^{9} / \mathrm{L}$; platelets $241 \times 10^{9} / \mathrm{L}$. 
- $\quad$ Serum urea and electrolytes- serum sodium $141 \mathrm{mmol} / \mathrm{L}$; serum potassium $3.4 \mathrm{mmol} / \mathrm{L}$; serum creatinine 76 umol/L; serum urea $6.2 \mathrm{mmol} / \mathrm{L}$;

- Liver profile and bone profile: serum bilirubin 25 umol/L (normal range 3-21); serum ALT $18 \mathrm{u} / \mathrm{L}$; serum alkaline phosphatise $84 \mathrm{u} / \mathrm{L}$; serum albumin $40 \mathrm{~g} / \mathrm{L}$; serum calcium $2.45 \mathrm{mmol} / \mathrm{L}$; serum calcium corrected 2.4 $\mathrm{mmol} / \mathrm{L}$.

- C- REACTIVE PROTEIN - Serum CRP $6.3 \mathrm{mg} / \mathrm{L}$ (normal range <10.0).

- ESTIMATED GFR - eGFR [MDRD formula] $61 \mathrm{~mL} / \mathrm{min}$ (normal range >60).

She was very well and asymptomatic by the evening of the next day following the procedure and she was discharged home on oral prednisolone $10 \mathrm{mg}$ orally daily for seven days. She has remained well two weeks after her discharge from hospital and her haemoglobin level remained stable.

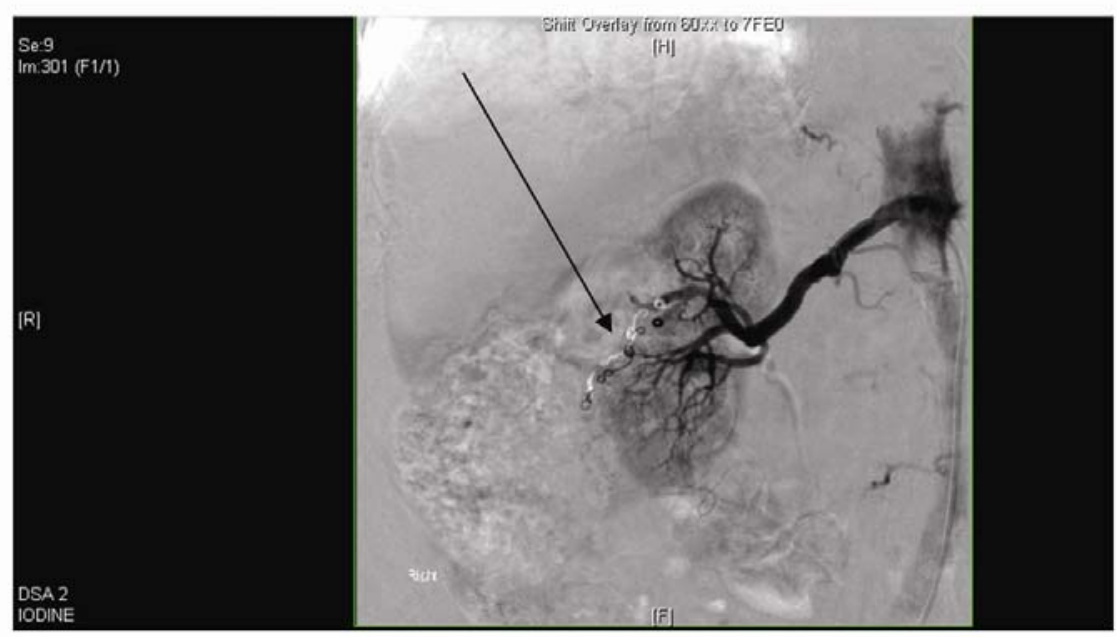

Figure 3. Post Embolization angiographic image showing coils in-situ (see arrow)

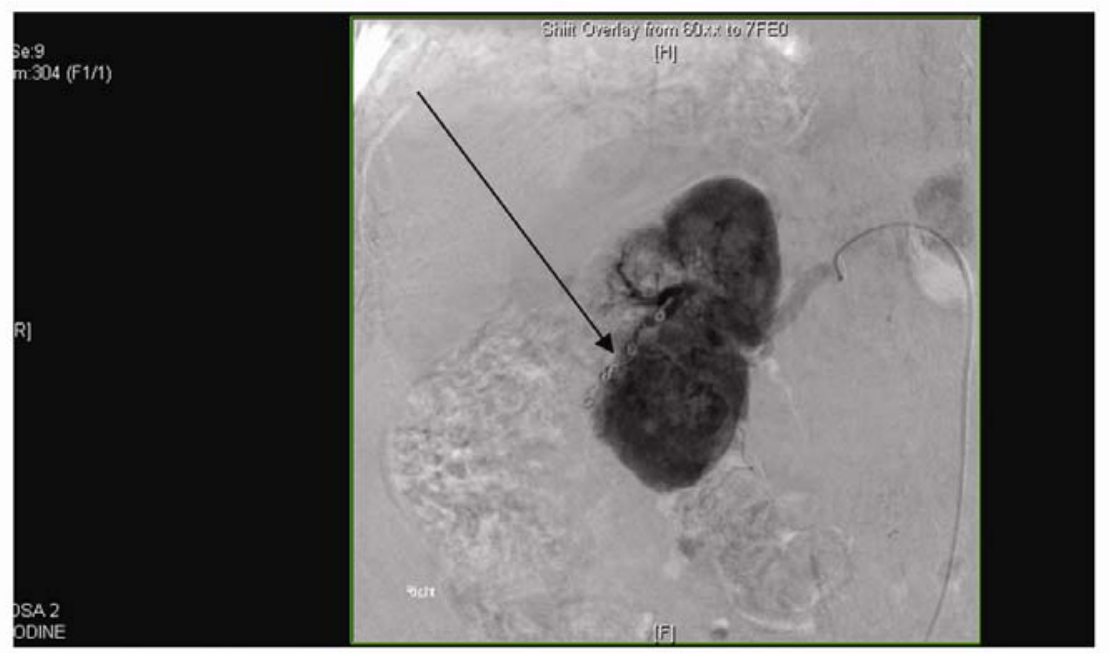

Figure 4. Angiogram demonstrates complete exclusion of the angiomyolipoma after embolization (see arrow) 


\subsection{Case number 2}

A 51-year-old lady was referred by her General Practitioner for ultrasound scan of abdomen because she had been experiencing right upper quadrant abdominal pain. She was asymptomatic otherwise.

She had ultrasound scan of the abdomen by an ultra-sonographer which was reported as showing the following findings:

The upper pole of the right kidney appeared normal but a normal lower pole of the right kidney was not demonstrable on the ultrasound scan due to a large $17 \mathrm{~cm} \times 16 \mathrm{~cm}$ solid hyper-echoic mass which appeared to be retroperitoneal and possibly arising from the right kidney. It appeared that the mass contained some fat. Therefore a retroperitoneal lipo-sarcoma should be excluded. The inferior vena cava could not be demonstrated due to the size of the mass.

The gallbladder was contracted and contained multiple $1.7 \mathrm{~cm}$ gallstones. The common bile duct was not dilated and measured approximately $6 \mathrm{~mm}$. The liver texture appeared satisfactory. The pancreas, spleen and left kidney appeared normal. The aorta was of normal calibre.

In view of the above findings a CT-scan of the thorax, abdomen and pelvis with contrast, was done and this was reported as follows:

There was a large predominantly fatty mass arising from the lower pole of the right kidney measuring $12.1 \mathrm{~cm} \times 8.9 \mathrm{~cm} \times$ $14.1 \mathrm{~cm}$, which was causing considerable mass effect and displacing the right kidney superiorly and the right colon (ascending colon) anteriorly. The mass lesion contained multiple vessels within and was well defined, with no evidence of invasion of surrounding viscera. Overall, the findings were consistent with a large angiomyolipoma which is a benign lesion of the kidney (see Figure 5).

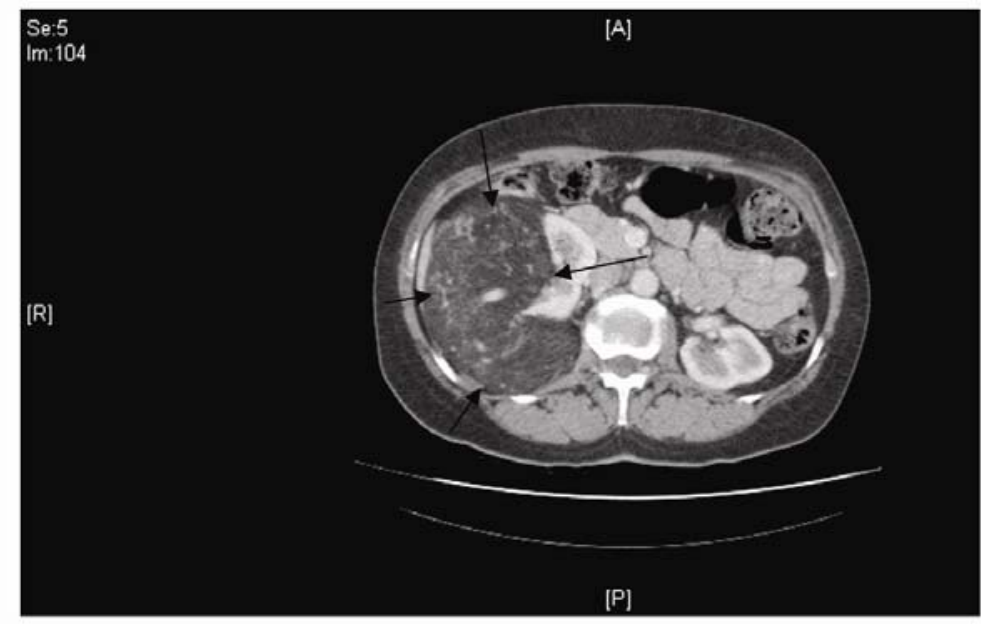

Figure 5. CT-Scan of abdomen done 8 days prior to emergency admission showing a large angiomyolipoma of right kidney (see arrows)

The left kidney had normal appearances. There was no CT evidence of underlying hydronephrosis.

The adrenal glands, pancreas, and spleen appeared unremarkable. There was no evidence of a focal lesion in the liver.

There was no evidence of any significant intra-abdominal or pelvic lymph-adenopathy. The visualised colon and small bowel appeared normal. A $7 \mathrm{~mm}$ (small) nodule in the left lobe (lung) was noted which was considered non-specific and 
benign but follow-up CT scan was recommended to be performed in three months if the patient is a smoker or six months if the patient is not a smoker. The central airway appeared fully patent with no obstructing endobronchial lesion. There was no evidence of any significant mediastinal lymph-adenopathy.

It was concluded that: There was evidence of a large angiomyolipoma of the right kidney therefore a urological referral was suggested in view of the fact that it was likely to require embolization due to the risk of bleeding from a lesion of this size; the non-specific lesion in the left upper lobe of lung should be followed up with a subsequent CT scan.

Eight days later the patient was admitted as an emergency following a telephone call referral. She presented with severe right loin pain. She was asymptomatic otherwise. She was not on any medication but stated she was allergic to scoline.

Her general examination and systematic examinations were on the whole normal and she was haemodynamically stable. Her blood pressure was 110/70 mm $\mathrm{Hg}$, and she had a regular heart rate of 80 per minute. On abdominal examination she was found to be tender in the right loin and right upper quadrant of her abdomen.

Her initial investigations on admission were reported as follows:

- Full blood count - Haemoglobin $11.3 \mathrm{~g} / \mathrm{dl}$ (normal range $11.5-16.5 \mathrm{~g} / \mathrm{dl}$ ), white blood cell count $17.6 \times 10^{9} / \mathrm{L}$ (normal range $4.0-11.0 \times 10^{9} / \mathrm{L}$ ), platelets $248 \times 10^{9} / \mathrm{L}$ (normal range $-150-450 \times 10^{9} / \mathrm{L}$ )

- Serum urea and electrolytes - Serum sodium $137 \mathrm{mmol} / \mathrm{L}$ (normal range 136 - $145 \mathrm{mmol} / \mathrm{L}$ ), Serum potassium $4.0 \mathrm{mmol} / \mathrm{L}$ (normal range 3.5 - $5.4 \mathrm{mmol} / \mathrm{L}$ ), serum creatinine $67 \mathrm{umol} / \mathrm{L}$ (normal range 53-97 umol/L), serum urea $5.6 \mathrm{mmol} / \mathrm{L}$ (normal range $2.5-6.7 \mathrm{mmol} / \mathrm{L}$ )

- Liver function test - serum bilirubin $12 \mathrm{umol} / \mathrm{L}$ (normal range, 3 -21 umol/L); serum ALT $13 \mathrm{u} / \mathrm{L}$ (normal range 10 - $35 \mathrm{u} / \mathrm{L}$ ); serum alkaline phosphatase $59 \mathrm{u} / \mathrm{L}$ (normal range 30 - $150 \mathrm{u} / \mathrm{L}$ ); serum albumin $37 \mathrm{~g} / \mathrm{L}$ (normal range $35-50 \mathrm{~g} / \mathrm{L})$.

- Serum C Reactive Protein (Serum CRP) - 3.7 mg/L (normal range < 10.0 mg/L).

- Serum amylase - 55 u / L (normal range 25-125 u / L)

- Estimated glomerular filtration rate (eGFR MDRD formula) $78 \mathrm{~mL} / \mathrm{min}$ (normal range $>90 \mathrm{ml} / \mathrm{min}$ )

- Clotting screen - INR 1.2 (normal range 0.9 - 1.1); PT 14.3 s (normal range 10016 s); Fibrinogen derived 2.7 g/L (normal range $1.7-4.0 \mathrm{~g} / \mathrm{L}$ )

- Urine examination by flow cytometry - white blood cells 41 / uL (normal range 0-40 / uL); Red blood cells 4/uL (0-35); epithelial cells normal.

- Urine culture - No growth

A provisional diagnosis of pain from a large angiomyolipoma of right kidney was made. Her initial treatment included analgesia, antiemetic, intravenous infusion and antibiotics (intravenous co-amoxiclav 1.2 grams eight hourly). She was initially stable over the first night of admission. However, she developed worsening right loin pain and increase in her heart rate up to between 106 and 119 beats per minute and her blood pressure dropped to 90 / $60 \mathrm{~mm} \mathrm{Hg}$. She was found to be pale and to have worsening tenderness on examination in her right loin and right side of her abdomen.

Her further investigations included:

- Full blood count which had revealed that her haemoglobin had dropped from $11.3 \mathrm{~g} / \mathrm{dl}$ to $6.4 \mathrm{~g} / \mathrm{dl}$ and because of this she was given blood transfusion.

- CT scan of abdomen and pelvis which revealed bleeding in the angiomyolipoma (see Figure 6). 
- Selective right renal artery angiography which confirmed bleeding from the inferior branch of the right renal artery feeding the angiomyolipoma and this was super-selectively embolized with 5 coils. Angiographic images at the end of the embolization confirmed the bleeding had stopped (see Figures 7 and 8).

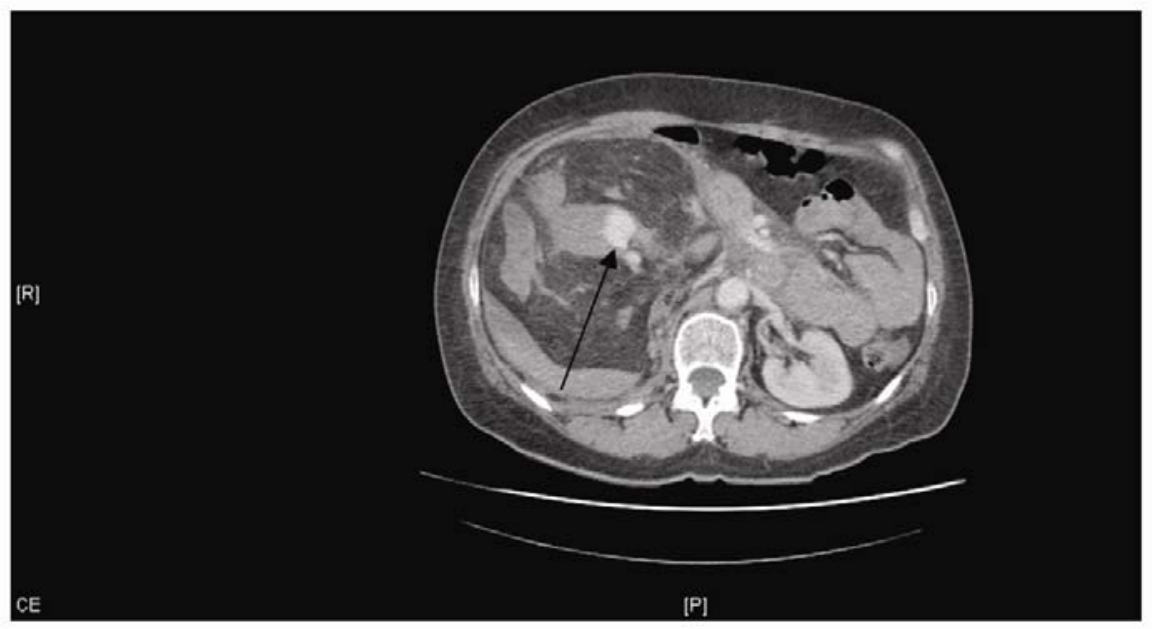

Figure 6. CT -scan of abdomen demonstrates large collection (haemorrhage) with a large pseudo aneurysm (see arrow)

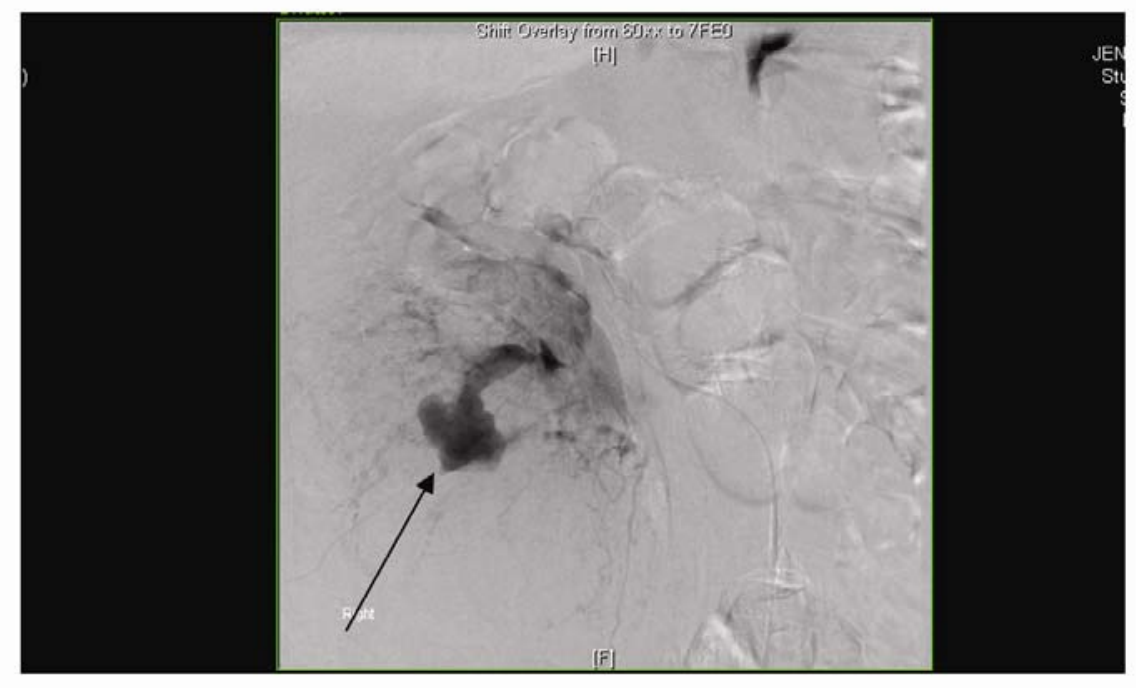

Figure 7. Angiogram reveals a large pseudo aneurysm with active contrast extravasations (see arrow)

She was transfused with 4 units of blood. She remained stable on the whole after the embolization procedure.

On the first day following the embolization procedure she developed pyrexia with her temperature ranging from 38 degrees centigrade to 39 degrees centigrade. She also had nausea and had some difficulty with breathing as well as cough which was clinically adjudged to be due to fluid overload for which she was given frusemide. She also had further investigations which were reported as follows:

- Full blood count - Haemoglobin $7.6 \mathrm{~g} / \mathrm{dl}$; white blood cell count $12.1 \times 10^{9} / \mathrm{L}$; platelets $103 \times 10^{9} / \mathrm{L}$ 
- $\quad$ Serum sodium $138 \mathrm{mmol} / \mathrm{L}$; serum potassium $4.0 \mathrm{mmol} / \mathrm{L}$; serum creatinine $72 \mathrm{umol} / \mathrm{L}$; serum urea $4.2 \mathrm{mmol} / \mathrm{L}$

- $\quad$ Serum CRP - $126.3 \mathrm{mg} / \mathrm{L}$ (raised)

- $\quad$ eGFR - $72 \mathrm{~mL} / \mathrm{min}$

- $\quad$ Blood culture - no growth

- Urinalysis by flow cytometric studies - normal

- $\quad$ Urine culture - No growth

- Legionella antigen - negative

- $\quad$ Pneumococcal antigen - Negative

- $\quad$ Sputum culture - Normal flora; and a growth of candida

She had further supportive treatment including the following:

- A start dose of gentamycin followed by a combination of intravenous tazosin 4.5 grams three times per day and vancomycin 1 gram twice daily upon the advice of the microbiologist

- $\quad$ Chest physiotherapy

- Two more units of blood transfusion after her temperature had settled

- $\quad$ Ibrupprofen $400 \mathrm{mg}$ orally three times per day

- $\quad$ Anti-emetics.

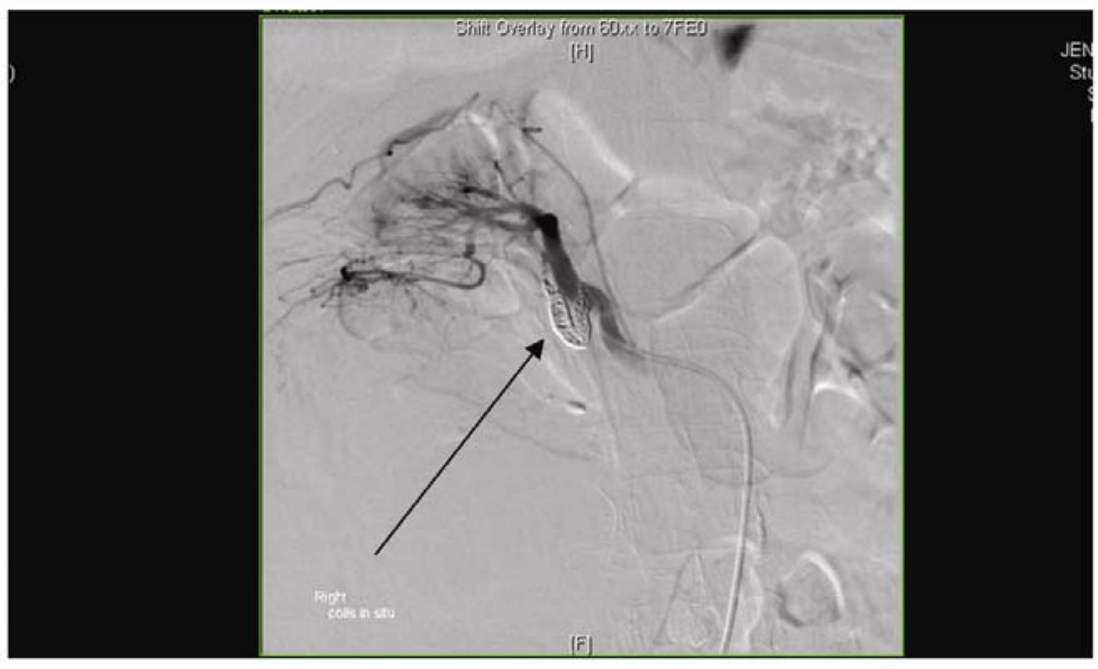

Figure 8. Selective embolization of the lower branch of right renal artery using coils and gel-foam resulting in successful exclusion of the aneurysm and stoppage of bleeding (see arrow)

Her symptoms were attributed to post embolization syndrome. By the 6th day post embolization her pyrexia had settled but her nausea persisted until the 9th post embolization day. She continued to have Intravenous tazosin and vancomycin until the 10th post embolization day upon the advice of the microbiologist to avoid any infection of the right kidney. Her intravenous antibiotics were stopped on the 10th post-embolization day and she was discharged home on oral augmentin $625 \mathrm{mg}$ three times a day for another four days. 
She was readmitted 8 days later to another hospital for 4 days. She was readmitted with a history of right upper quadrant discomfort/pain and increasing shortness of breath of 4 days duration prior to her admission. On examination she was noted to have a temperature of 37.7 degrees centigrade; she had slightly diminished air entry at the bases of the chest; she was tender in right side of her abdomen. She had further investigations including: full blood count which was normal; urine culture which was normal; serum CRP level which was raised at $88.2 \mathrm{mg} / \mathrm{L}$; CT scan of thorax and abdomen which revealed minimal right sided basal atelectasis and evidence of old haemorrhage in the lower pole of the right kidney but no evidence of any new perinephric or intra-peritoneal bleed. She was given intravenous tazosin, and she had chest physiotherapy. She also had paracetamol, codeine, ciprofloxacin (500 mg orally b d), metronidazole and after 4 days of admission her symptoms resolved and she was discharged home on a three week course of oral ciprofloxacin. At the time of her discharge her serum CRP had come down to $27.8 \mathrm{mg} / \mathrm{L}$.

Fifteen days after her second admission and 34 days after she had embolization she was readmitted because of nausea and vomiting and right sided loin pain. Her general examination was unremarkable, her chest was clinically clear but she was tender in the right loin/right upper quadrant of her abdomen. She had further investigations which were reported as follows:

- Full blood count- Haemoglobin $12.8 \mathrm{~g} / \mathrm{dl}$; white cell count $6.9 \times 10^{9} / \mathrm{dl}$; platelets $303 \times 10^{9} / \mathrm{L}$.

- Serum urea and electrolytes -serum sodium $137 \mathrm{~m}-\mathrm{mol} / \mathrm{L}$; serum potassium $4.2 \mathrm{~m}-\mathrm{mol} / \mathrm{L}$; serum creatinine 69 u-mol/l; serum urea $4.9 \mathrm{~m}-\mathrm{mol} / \mathrm{L}$.

- $\quad$ Serum CRP - $27.8 \mathrm{mg} / \mathrm{L}$.

- $\quad$ eGFR (MDRD formula) $76 \mathrm{~mL} / \mathrm{min}$.

- Blood culture - no growth.

- $\quad$ MRSA screen groin and throat no growth.

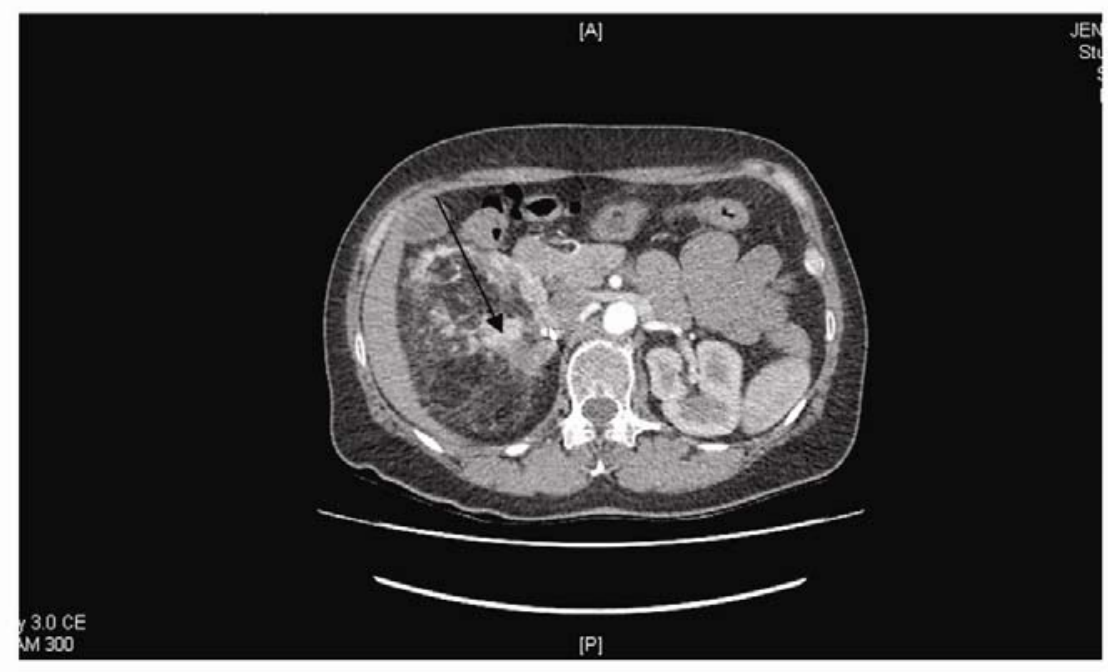

Figure 9. CT- scan of abdomen about three and half months after the embolization procedure which shows shrinkage of the angiomyolipoma and no haemorrhage

During this admission (3rd admission), she was treated with intravenous infusion; clexane injections as well as she continued to take ciprofloxacin. After 4 days her symptoms subsided and she was discharged home. At the time of her discharge she had further blood tests which were reported as follows: 
Serum urea and electrolytes -all normal; Liver function tests - all normal; Bone profile - all normal; Serum CRP 13.2 mg/L (this has come down to near normal (normal range < $10.0 \mathrm{mg} / \mathrm{L}$ ); eGFR $81 \mathrm{ml} / \mathrm{min}$ (normal range (>60 ml/min).

She was discharged home to continue her course of antibiotics to avoid infection of the organised haematoma in her right kidney.

She had another CT- scan of abdomen and pelvis (about three and half months later) which confirmed that there had not been any further bleeding in the residual angiomyolipoma (see Figure 9). She has remained well after her final discharge from hospital and her haemoglobin level remained stable at $12.8 \mathrm{~g} / \mathrm{dl}$.

\section{Discussion}

Angiomyolipoma is composed of different proportions of fat (adipose tissue), blood vessels and smooth muscle which emanates from abnormal proliferation. It has rarely been referred to as choristoma due to the presence of tissue type which did not originate from the kidney. Angiomyolipoma is increasingly understood to be a benign neoplasm based upon its clinical sequelae and molecular characteristics ${ }^{[7]}$.

Two types of angiomyolipoma of kidney which have been described include:

(a) The sporadic type which occurs sporadically in individuals with no clinical evidence of tuberous scleroris (epiloia). The sporadic variety of angiomyolipoma tends to be slower growing and is associated with better sequelae in comparison with the type which is associated with tuberous sclerosis. Nevertheless, it has been stated ${ }^{[7]}$ that even in the sporadic form female and pregnant patients were noted to have a more complicated angiomyolipoma. Henske and associates ${ }^{[8]}$, as well as L'Hostis and associates ${ }^{[9]}$, discovered the presence of oestrogen and progesterone receptors in angiomyolipomas of the sporadic type.

(b) Angiomyolipomas which are part of the tuberous sclerosis complex (TSC). These tumours most often are bilateral; they tend to have multi-centric foci; they tend to bleed more frequently in comparison with the sporadic types of angiomyolipomas ${ }^{[10,11]}$. Steiner and associates ${ }^{[2]}$ illustrated this group have worse outcome due to the fact that they are associated with faster growth rates in comparison with the sporadic variant (67\% versus 21\%) and earlier need for operative intervention (50\% versus $28 \%$ ).

The diagnosis of rupture or bleeding from angiomyolipoma depends upon imaging. Ultrasound scan is rapid, and non-invasive and sensitive for the detection of haemorrhage but is less effective in defining the nature of the condition or the source of the haemorrhage. CT scan is the imaging modality of choice in view of the fact that it can reveal the source of bleeding. In the series of Argente and associates ${ }^{[12]}$, it detected in $92.6 \%$ of cases the haematoma and its origin. A fat density, with non-calcified renal mass remains the most important diagnostic finding of angiomyolipoma on CT-scan. If calcification is detected then renal cell carcinoma is the most important differential diagnosis. Albi and associates ${ }^{[13]}$ as well as Zhang and associates ${ }^{[14]}$ also stated that CT scan is the method of choice to demonstrate perirenal haemorrhage (with a sensitivity of 100\%) and if performed during haemorrhage it has been found to identify all causes of Wunderlich's syndrome due to angiomyolipoma.

Most angiomyolipomas are small and asymptomatic however, some authors have suggested that in up to $80 \%$ of patients when the size of the angiomyolipoma reaches $4 \mathrm{~cm}$ or greater, half of them present with abdominal or flank pain and $10 \%$ to $20 \%$ haematuria or palpable mass ${ }^{[15]}$.

There are three recognised aetiologies for spontaneous rupture of a renal angiomyolipoma. In Wunderlich's syndrome ${ }^{[6]}$, a spontaneous retroperitoneal haemorrhage of non-traumatic origin occurs in up to $50 \%$ with angiomyolipomas greater than four centimetres. Secondly, a renal angiomyolipoma may manifest with bleeding or rupture after trauma, even with a 
low velocity mechanism. Thirdly, on rare occasions rupture/bleeding of angiomyolipoma can occur during pregnancy. The tendency to rupture has been attributed to the weak, elastin-poor vascular structure in the angiomyolipoma ${ }^{[7]}$.

The main complication of angiomyolipoma is retroperitoneal bleeding, which can be life threatening ${ }^{[1,3]}$. It has been stated that the bleeding tendency originates from irregular, aneurismal, tortuous blood vessels that constitute the angiogenic component of the tumour ${ }^{[16,18]}$.

Other authors have also stated that the larger the tumour, the greater is the risk of bleeding; $4 \mathrm{~cm}$ is the usually accepted cut-off point ${ }^{[3,15,20,21]}$.

There is general agreement that patients with asymptomatic angiomyolipoma larger than $4 \mathrm{~cm}$ should be treated, as should those with symptomatic lesions of any size ${ }^{[17,22]}$. Treatment options for angiomyolipoma include: total nephrectomy; partial nephrectomy; cryoablation; radiofrequency ablation and trans-catheter selective arterial embolisation ${ }^{[6]}$.

The treatment of renal angiomyolipoma was predominantly surgical, until Moorhead and associates in 1977 described the first case of selective arterial embolization of these lesions ${ }^{[23]}$. Most authors currently regard partial nephrectomy as the treatment modality of choice for many non-haemorrhagic tumours. There is no significant loss of kidney function after surgery, even in patients with one kidney. Urinary fistulae are the most common complications which occur in about 10 percent of patients after partial nephrectomy and this is followed by infection.

Pursuant to the first report of angiographic embolization of angiomyolipoma, as a result of recent developments in interventional radiology, the technique is becoming a common treatment modality in the management of this entity. Some of the advantages of selective embolization for angiomyolipoma include:

- Preservation of functional renal parenchyma

- Ability to selectively embolize bleeding vessels and thus preserving non bleeding vessels

- Circumvention of the need for general anaesthesia and surgical operation / excision thus reducing the duration of post procedure recovery period, as well as avoiding an operative wound healing and surgical scar.

Indications for embolization in angiomyolipoma include:

- Acute haemorrhage due to spontaneous rupture

- Symptomatic tumour in patients with co-morbidities who are poor operative candidates in view of their risks

- Patients who have limited renal reserve.

Nephron-sparing procedures such as tumourectomy and selective embolization are considered the procedures of choice which preserve the renal parenchyma ${ }^{[1]}$.

Absolute ethanol without or with lipiodol ${ }^{[16,19,24-26]}$, $\operatorname{coils}^{[18,25]}$, polyvinyl alcohol ${ }^{[18,25]}$, or gelatine sponge ${ }^{[25]}$, have been used successfully as embolization materials. Some authors are of the view that Ethanol is superior to other materials in view of its liquidity and high occlusion potential ${ }^{[16,19,27]}$.

With regard to complications ensuing from selective arterial embolization of angiomyolipomas, Bestard-Vallejo and associates ${ }^{[28]}$ reported on a retrospective analysis of 20 cases of patients with renal angiomyolipoma who were treated in their centre from March 1996 to March 2006. They stated that patients suffering from tuberous sclerosis (20\%) showed multiple bilateral tumours, with size similar to the rest of the patients. Diagnosis of tuberous sclerosis was the only factor attached to spontaneous rupture of those lesions. Four of 9 emergency embolized patients (44.4\%) required second treatment because of second haemorrhage, and 4 of the 16 embolization episodes (25\%) developed post-embolization 
syndrome, both with no predicting factors attached. Reduction of less than one third of the initial diameter was observed in $58.4 \%$ of embolized tumours, which used to be multiple, bilateral and of size larger to the rest. They did not observe any significant difference in serum creatinine before and after treatments.

Bestard-Vallejo and associates ${ }^{[28]}$ also stated that in their series complications were observed in $18.7 \%$ of cases in which pleural effusion and sepsis were the most common. Nelson and Sanda ${ }^{[1]}$ reported that the complication rate of selective arterial embolization was observed in $10 \%$ of cases, the most common complication being abscess formation which occurred in $5 \%$ of cases and pleural effusion which occurred in $3 \%$ of cases. So far a single case of death as a result of respiratory failure was reported in a patient with severe pre-existing lung disease. Other less common complications reported include migration of the embolization materials, sterile liquefaction, and reactive pleural effusion ${ }^{[24,29,30]}$. Eighty five percent of patients developed a post-embolization syndrome of flank pain, fever, leucocytosis and nausea attributable to inflammatory mediators. The treatment of this post-embolization syndrome is supportive with antipyretics, anti-emetics and analgesics and most patients recover within 2 to 5 days ${ }^{[29]}$.

Bissler and associates ${ }^{[31]}$ stated that although an effective renal-sparing procedure, embolization most often is associated with an inflammatory response that causes significant fever and pain that can last for several days despite the use of acetaminophen and reported cases showed that 49 of 55 patients who underwent embolization developed this syndrome. They also stipulated that the use of such non-steroidal anti-inflammatory drugs as aspirin is contraindicated because of their adverse effects on platelet function. To reduce pain and fever associated with post-embolization syndrome, Bissler and associates ${ }^{[31]}$ changed their clinical management of patients, post-embolization to include a tapering dose of prednisolone over a 2-week period. Nine patients underwent this pharmacological intervention, and one patient abstained. All patients were monitored for pain and fever. They found that only two patients treated with steroids developed fever, which was assuaged with acetaminophen, and no patient reported pain. The tapering dose of prednisolone was well tolerated, and there were no post-procedure infections. They concluded that the use of a short-term tapering dose of prednisolone appeared to reduce post-embolization syndrome compared with the reported literature and improved patient comfort. In addition Bissler and associates ${ }^{[31]}$ stated that the incidence of post-embolization syndrome among the 55 treated patients with angiomyolipoma that was reported in the literature was $89 \%$ and this rate was similar to rates seen after embolization of other tissues ${ }^{[32]}$.

Yinglu and associates ${ }^{[33]}$ conducted a randomized, double-blinded and controlled trial on 120 patients with primary liver cancer who were divided into four groups, with 30 patients in each group. The aim of their study was to observe the effect of ginsenosides (GS) and dexamethasone (Dex) in alleviating the post-embolization syndrome following trans-catheter arterial chemoembolization (TACE). The changes of clinical symptoms and laboratory tests before TACE and on 3 and 7 days after TACE were observed. They reported that the results of the study indicated that Dex combined with GS not only markedly decreased the occurrence ratio and duration of such symptoms as nausea, vomiting, and fever, but also significantly reduced levels of total bilirubin, glutamic oxaloacetic transaminase, and glutamic-pyruvic transaminase (AST) and improved the Child-Pugh stage of liver function as compared with single use of GS or Dex. They concluded that although single use of Dex or Gs may improve some indices of adverse effects after TACE, the combination of Dex and GS can systematically prevent and treat the post-embolization syndrome after TACE.

Feng and associates ${ }^{[34]}$ conducted a study to observe the effect of ginsenosides (GS) and low dose glucocorticoid in preventing and treating the post-embolization syndrome following trans-catheter arterial chemo-embolization (TACE). In this study eighty patients with primary liver carcinoma were randomly divided into 4 double-blinded groups, with 20 patients in each group. The patients in groups A, B, C, and D were treated with placebo, dexamethasone (Dex), ginsenoside (GS), Dex and GS, respectively. The changes of clinical symptoms and laboratory tests after TACE were observed. Feng and associates ${ }^{[33]}$ reported that dexamethasone combined with ginsenoside markedly decreased the occurrence ratio and lasting time of the symptoms such as nausea, vomiting, fever and pain, and protected the function of liver as compared with the placebo $(P<0.05)$. They also reported that single use of dexamethasone or ginsenoside 
improved some symptoms in comparison with placebo, but it was not as good as the combination of dexamethasone and ginsenoside. They concluded that dexamethasone combined with ginsenoside can effectively prevent and treat the post-embolization syndrome following TACE.

\section{Conclusions}

Development in interventional radiology has made it possible for spontaneous haemorrhage emanating from angiomyolipoma to be treated by selective renal artery angiography to identify and localise the site of bleeding and to embolize the bleeder; selective arterial embolization is an attractive alternative to surgical intervention for spontaneous haemorrhage for angiomyolipoma; if further spontaneous bleeding occurs subsequently this could perhaps be treated by another embolization and perhaps surgery in the form of partial nephrectomy or tumourectomy or nephrectomy reserved for the possible rare event of subsequent further bleeding or non-availability of an interventional radiologist to perform the embolization. Selective renal artery angiography and embolization is a safe and effective treatment modality for spontaneous haemorrhage into angiomyolipoma which avoids general anaesthesia and open surgical operation.

Even though the reasons for post-embolization syndrome are multi-factorial, the experience gained in the management of the first case may suggest that the use of steroids about the time of embolization may help avoid or reduce the severity of post-embolization syndrome.

\section{References}

[1] Nelson C P, Samda M G. Contemporary diagnosis and management of renal angiomyolipoma. J Urol. 2002; 168 : $1315-1325$. http://dx.doi.org/10.1016/S0022-5347(05)64440-0

[2] Steiner M S, Goldman S M, Fishman E K, Marshall F F. The natural history of renal angiomyolipoma. J Urol. 1993; 150: 1782-1786. PMid:8230504

[3] Harabayashi T, Shinohara N, Ketano H, Nonomura K, Shimizu T, Koyanagi T. Management of angiomyolipoma associated with tuberous scleroris complex. J Urol. 2004; 171: 102-105. PMid:14665854 http://dx.doi.org/10.1097/01.ju.0000100100.36354.61

[4] Morgan G S, Straumfjord J V, Hall E J. “Angiomyolipoma of the kidney.” Journal of Urology. 1951; 65: 525-527. PMid:14825528

[5] Grawitz P. “Demonstration Eines Grossen Angio-Myo-Lipomas der Niere.” Disch Med Wochenschr. 1900; $26: 290$.

[6] Wunderlich C R. Handbuch der Pathologie und Therapie 2nd ed. Stuttgart. Ebner and Seubert. 1856.

[7] Lim C H, Mulvin D. Embolisation of Bleeding Renal Angiomyolipoma in Pregnancy. Open Journal of Urology. 2011 ; $1: 25-27$. http://dx.doi.org/10.4236/oju.2011.13007

[8] Henske E P, Ao X, Short M P, Greenberg R, Neumann H P, Kwiakowski D J. "Frequent Progesterone Receptor Immunoreactivity in Tuberous Scleroris Associated Renal Angiomyolipomas.” Modern Pathology. 1998 July; 2(7): 665-668.

[9] L’ Hostis H L, Deminiere C, Ferreira J M. “Spontaneous Haemorrhage during Pregnancy Secondary to Renal Angiomyolipoma ”. International Journal of Urology. 1999; 56: 188-189.

[10] Stillwell J T, Gomez M R, Kelalis P P. “Renal lesions in Tuberous Sclerosis.” Journal of Urology. 1987 September; 138: $477-481$. PMid:3625844

[11] Bernstein J, Robbins T O, Kissane J M. “The Renal lesions in Tuberous Sclerosis “. Seminars in Diagnostic Pathology. 1986 May; 3(2): 97-105. PMid:3616220

[12] Gimeno Argente V, Bosquet Sanz M, Ramírez Backhouse M, Trassiera Villa M, Arlandis Guazma S, Jiménez Gruz J F. Actas Esp. 2007; 31(5): 521-527.

[13] Albi G, Del Campo L, Tagarro D. Wunderlich’s syndrome: causes, diagnosis and radiological management. Clin Radiol. 2002; 57: 840-845. PMid:12384111

[14] Zhang J Q, Feiding J R, Zou K H. Etiology of spontaneous perirenal hemorrhage: a meta-analysis. J Urol 2002; $167: 1593-1594$. http://dx.doi.org/10.1016/S0022-5347(05)65160-9

[15] Osterling J E, Fishman E K, Goldman S M. The Management of Renal Angiomyolipoma. The Journal of Urology. 1986; 135(6): 1121-1124. PMid:3520013

[16] Soulen M C, Faykus M H Jr, Shllansky-Goldberg R D, Wein A J, Cope C. Elective embolization for prevention of hemorrhage from angiomyolipoma. J Vasc interv Radiol. 1994; 5: 587-591. http://dx.doi.org/10.1016/S1051-0443(94)71558-X 
[17] Van Baal J G, Smith N J, Keenan J N, Lindout D, Verhoef S. The evolution of renal angiomyolipoma in patients with tuberous sclerosis. J Urol. 1994; 152: 35-38. PMid:8201681

[18] Mourikis D, Chatziioannou A, Antoniou A, Kehagias D, Cikas D, Vlahos L. Selective arterial embolization in the management of symptomatic renal angiomyolipoma. Eur J Radiol. 1999; 32: 153-159. http://dx.doi.org/10.1016/S0720-048X(98)00179-X

[19] Earthman W J, Mazer M J, Winfield A C. Angiomyolipoma in tuberous sclerosis: Subselective embolotherapy with alcohol, with long-term follow-up study. Radiology. 1986; 160: 437-441. PMid:3726123

[20] De Luca S, Terrone C, Rosetti S R. Management of renal angiomyolipoma: a report of 53 cases. BJU Int. 1999; 83: $215-218$. [Medline] http://dx.doi.org/10.1046/j.1464-410x.1999.00932.x

[21] Tsai H N, Chou Y H, Shen J T, et al. The management strategy of renal angionyolipoma. Kaohshiung J Med Sci. 2002; 18: 340346 [Medline] PMid:12380324

[22] Kennelly M J, Grossman H B, Cho K J. Outcome of urinalysis of 42 cases of renal angiomyolipoma. J Urol. 1994; 152: 1988-1991 [Medline] PMid:7966657

[23] Moorehead J D, Fritzsche P, Hardley H L. Management of hemorrhage secondary to renal angiomyolipoma with selective arterial embolization. J Urol. 1977 Jan; 117(1): 122-123 [PubMed] PMid:830960

[24] Lee W, Kim T S, Chung J W, Han J K, Kim S H, Park J H. Renal angiomyolipoma embolotherapy with a mixture of alcohol and and iodized oil. J Vasc Interv Radiol. 1998; 9: 255-261 [Medline] http://dx.doi.org/10.1016/S1051-0443(98)70266-0

[25] Han Y M, Kim J K, Roh B S, et al. Renal angiomyolipoma: selective arterial embolization: effectiveness and changes in angiomyoneric components in long-term follow-up. Radiology. 1997; 204: 65-70. PMid:9205224

[26] Kothary N, Soulen M C, Clark T W, et al. Renal angiomyolipoma long-term results after arterial embolization. J Vasc Interv Radiol. 2005; 16: 45-50. PMid:15640409 http://dx.doi.org/10.1097/01.RVI.0000143769.79774.70

[27] Park J H, Kim W S, Han M C, Lee C W. Renal arterial embolization with absolute ethanol. J Korean Med Sci. 1987 ; 2: 13-18. [Medline] PMid:3269241

[28] Bestrad-Vallejo J E, Trilla-Herrerra E, Celman-Domenech A, Pérez-Lafuente M, de Torres-Ramirez I, Morote-Robles J. Renal angiomyolipomas: presentation, treatment, and outcome of 20 cases. Actas Urol Esp. 2008; 32(3): 307-315. PMid:18512387

[29] Hamlin J A, Smith D C, Taylor F C, McKinney J M, Ruckle H C, Hadley H R. Renal Angiomyolipomas: Long-Term Follow-up of Embolization for Acute Haemorrhage. Can Assoc Radiology Journal. 1997 Jun; 48 (3): 191-197. PMid:9193419

[30] Ewatt D H, Diamond N, Rees C, Sparagana S P, Delgado M, Batchelor L, et al. Long-term outcome of transcatheter embolization of renal angiomyolipoma due to tuberous sclerosis complex. J Urol. 2006; 174(5): 1764-1768.

[31] Bissler J J, Recadio J, Donnelly L F, Johnson N D. Reduction of Postembolization Syndrome after Ablation of Renal Angiomyolipoma. American journal Kidney Diseases. 2002 May; 39(5): 966-971. PMid:11979340 http://dx.doi.org/10.1053/ajkd.2002.32770

[32] Slomka M, Radwan P. The evaluation of clinical results of hepatic artery embolization Mater Med Pol. $1992 ; 24 ; 193-195$. PMid:1307653

[33] Yinglu F, Changquan L, Xiaofeng Z, Bai L, Dezeng Z, Zhe C. A new way: alleviating postembolization syndrome following transcatheter arterial chemoembolization. J Altern Complement Med. 2009 Feb; 15(2): 175-181. PMid:19216654 http://dx.doi.org/10.1089/acm.2008.0093

[34] Feng Y L, Ling C Q, Zhu D Z, Yu C Q, Chen Z, Li B. Ginsenosides combined with dexamethasone in preventing and treating postembolization syndrome following transcatheter arterial chemoembolization: a randomized, controlled and double-blinded prospective trial. Zhong Xi Yi Jie Xue Bao. 2005 March; 3(2): 99-102. PMid:15763053 http://dx.doi.org/10.3736/jcim20050205 